\title{
Prevalence of Multiple Sclerosis in British Columbia
}

\author{
Vincent P. Sweeney, Adele D. Sadovnick and Vilma Brandejs
}

\begin{abstract}
A province wide prevalence study on multiple sclerosis (MS) was conducted in British Columbia (B.C.). The prevalence date was July 1, 1982. The major portion of this study was a review of all the files of neurologists practicing in B.C. as this was judged to be the most accurate source for identifying MS patients. 239,412 neurologists' files were hand searched by one researcher using modified Schumacher criteria for classification. Other sources used during the study for identifying MS patients were the MS Clinic, general practitioners, ophthalmologists, urologists, specialized facilities such as long term care facilities and rehabilitation centres, and patient self-referrals.

A total of 4,620 non-duplicated cases were identified and classified. 4,112 of these (89\%) were classified according to information contained in neurologists' records.

The prevalence estimate for definite/probable MS in B.C. was $93.3 / 100,000$ population. This increased to $130.5 / 100,000$ population if possible MS and optic neuritis were also included. These rates are among the highest reported in Canada or elsewhere. The cooperation of B.C. neurologists made this study unique in its scope and accuracy of diagnosis.
\end{abstract}

RÉSUMÉ: Prévalence de la sclérose en plaques en Colombie-Britannique Nous avons étudié la prévalence de la sclérose en plaques (SEP) à l'échelle de la province de Colombia-Britannique (C.B.). Le jour de prévalence fut fixé au $1^{\text {er }}$ juillet 1982. La principale source de données consiste en une revue des dossiers des neurologues pratiquant en C.B., car nous croyons qu'il s'agit là de la meilleure méthode d'identification des patients. Un des chercheurs a lui-même vérifé chacun des 239,412 dossiers de neurologues, se servant des critères modifiés de Schumacher pour la classification. Les autres sources de données furent: La clinique de SEP, les praticiens généraux, les ophtalmologues, les urologues et les institutions spécialisées de soins prolongés ou de réhabilitation et finalement les patients s'identifiant eux-mêmes.

Nous avons identifié et classifié un total de 4,620 cas. $89 \%$, soit 4,112 , purent être classifiés grâce aux renseignements provenant des dossiers des neurologues. Les estimés de prévalence en C.B., pour les cas certains et probables étaient de $93.3 / 100,000$ de population. Ce chiffre devient $130.5 / 100,000$ de population si on inclut les cas de SEP possibles et ceux de névrite optique. Ces taux sont parmi les plus élevés rapportés au Canada ou ailleurs. La coopération des neurologues de Colombie-Britannique a permis une telle étude, unique quant à son étendue et quant à l'exactitude du diagnostic.

Can. J. Neurol. Sci. 1986; 13:47-5I

Epidemiological studies of multiple sclerosis (MS) have made major contributions to the current understanding of this unique disease. Populations living in high risk geographic areas are most susceptible. Migration studies and the demonstration of clusters suggest that an environmental factor, likely infectious, is involved in the etiology of MS.' Genetic predisposition to MS is probably also a factor. ${ }^{2,3}$ Canada is considered a high-risk geographic zone as are the northern states of the United States. However, prevalence rates reported in Canada vary from $21.2 / 100,000$ in Halifax County, Nova Scotia ${ }^{4}$ to $111 / 100,000$ in Saskatoon, Saskatchewan. ${ }^{5}$ This difference may relate to environmental or genetic factors, but may also be explained by differences in the accuracy of diagnosis, availability of medical care at different periods of time, and methods of case ascertainment. For example, the Saskatoon study used health care insurance files to identify cases ${ }^{5}$ and this would be expected to result in relatively complete case identification. A province wide prevalence study of MS has never been conducted in British Columbia (B.C.), a province likely to have a high prevalence for MS because of its geographic and ethnic characteristics.

The basic unit in medical epidemiological studies is the case with an accurate diagnosis. For multiple sclerosis, the most accurate diagnosis in life is made by neurologists. In addition, neurologists are more likely to detect early and benign cases.

From the Division of Neurology, Department of Medicine (Dr. Sweeney, Mrs. Brandejs) and Department of Medical Genetics (Dr. Sadovnick), University of British Columbia, Vancouver

Received July 16, 1985. Accepted in revised form November 21, 1985

Reprint requests to: Dr. V.P. Sweeney, Division of Neurology, Department of Medicine, Vancouver General Hospital, \#222 - 2775 Heather Street, Vancouver, British Columbia, Canada V $5 Z 3 J 5$ 
They also have access to diagnostic tests such as cerebrospinal fluid analyses, evoked potentials, CT scans and other radiological procedures. ${ }^{6}$ Neurologists are probably more inclined to gather information on age of onset and clinical course of MS and to inquire about associated factors. Information available from neurologists' files therefore allows more accurate classification of ascertained cases.

We conducted a province-wide prevalence study that included multiple sources of case ascertainment, but which allowed comparison with cases identified and classified by neurologists. The files of all participating neurologists were hand searched and cases identified from this source formed the core of the present study.

\section{MATERIALS AND MethodS}

\section{Confidentiality}

Extreme care was taken to guarantee the confidentiality of all personal and identifying information on individuals ascertained through the study. Guidelines to ensure this confidentiality were developed and then approved by the Canadian Medical Protective Association, the B.C. College of Physicians and Surgeons, and the Section of Neurology, B.C. Medical Association.

\section{Sources of Case Identification}

\section{a) Neurologists}

During the period of the study, 43 neurologists were practicing in B.C. The files of $37(86.0 \%)$ were searched. Two neurologists $(4.7 \%)$ did not wish to participate and the remaining four neurologists $(9.3 \%)$ specialized in areas of neurology which did not include MS patients. All files of neurologists who agreed to participate were hand searched and all suspect MS cases were selected for review. Cases meeting the criteria for inclusion in this study (see section 3 ) were identified. Demographic information was extracted from the medical files and entered onto data sheets. Information on the progression of disease and any other relevant clinical data were also recorded. Following this same procedure, records of the two neuro-ophthalmologists practicing in the province and the files of the Multiple Sclerosis Clinic, University of British Columbia, Health Sciences Centre Hospital were also searched. All file searches were conducted by one of us (VB).

All patients identified from the files of the two neuroophthalmologists had seen at least one neurologist either in private consultation or through the MS Clinic. All patients attending the MS Clinic were seen by at least one of the five Clinic neurologists.

\section{b) Physicians, Other than Neurologists, and Specialized Facilities}

All general practitioners, ophthalmologists, urologists, and administrators of long term care facilities and specialized treatment centres in B.C. were contacted by mail and asked to provide relevant information on all patients known to them who had MS, possible MS, optic neuritis, or MS as a differential diagnosis.

\section{c) Self Referrals}

Self registration forms were distributed to members of various MS groups in B.C. These forms requested the following information: full name, maiden name (if applicable), date and place of birth, name of neurologist and/or general practitioner, and permission to contact the given physician(s) for confirmation of diagnosis. These forms were completed and returned by the individuals. In addition, public advertising in local newspapers requested persons with MS to contact the study centre.

\section{Classification of Cases}

The Schumacher diagnostic criteria for $\mathrm{MS}^{7}$ were used with the exception that cases diagnosed by neurologists as suffering from definite/probable MS whose ages of onset fell outside the Schumacher range of 10-50 years were accepted as MS. The diagnostic criteria for possible MS as outlined by Rose et al ${ }^{8}$ and MacDonald and Halliday ${ }^{9}$ were used in this study. Using these criteria, cases were classified into one of five categories:

1) Definite/Probable MS

2) Possible MS

3) Optic Neuritis

4) MS - a differential diagnosis

5) A diagnosis of MS could not be made at the time of examination and no differential diagnosis was suggested by the neurologist. The patient was undiagnosed pending future developments.

a) Classification of Cases Identified from the Search of the Files of Neurologists, MS Clinic, and Neuro-Ophthalmologists

In the majority of cases, patients were classified according to the diagnosis on the chart. If only symptoms and signs were recorded and there was no final diagnosis stated, the research assistant consulted with both the attending neurologist and the neurologist involved in this study (VPS) prior to classifying the case into one of the five categories.

If a case was identified from a source other than a neurologist as well as from the search of neurologists' files, the neurologist's diagnosis had precedence.

If a person was seen by more than one neurologist and the diagnosis was different, e.g. possible MS and definite MS, the most firm MS diagnosis was used in the estimation of the prevalence.

\section{b) Classification of Cases Identified Only from Non-Neurologist Sources}

Cases identified from sources other than neurologists were classified as definite/probable MS for the purpose of the calculation of prevalence unless a diagnosis of possible MS, optic neuritis, or MS as a differential diagnosis was indicated by the registering source. The rationale for this was that these persons utilize MS facilities and services and therefore are part of the "MS load" in the population.

\section{Calculation of Prevalence Rates}

Data were cross-referenced both manually and with the use of a computer to avoid duplicate entry of cases.

Prevalence refers to the total number of MS patients alive at a given point in time (prevalence date - July 1,1982 ) living in defined area (the province of British Columbia).

Data collection took 2 years to complete (July, 1982 - June, 1984). The prevalence date was set as July 1,1982 . If a case was ascertained after the prevalence date, the case was only included in the study if there was accurate documentation that the onset of MS was prior to July 1, 1982. Prevalence rates were calcu- 
lated only for individuals diagnosed as having clinically definite/probable MS, possible MS, or optic neuritis. Persons with MS as a differential diagnosis or those who were undiagnosed pending further developments (Table 2) were excluded from the calculation of prevalence rates although the identification of such patients was thought to be important for future follow-up studies.

\section{a) Deaths}

The study case list was linked with provincial death lists up to and including 1980 to identify those persons who had died in B.C. among the ascertained cases not known to be alive on prevalence date. Provincial death lists are not available, as yet, for record linkage for the years 1981 - 1982. Therefore the number of deaths likely to have occurred in 1981 and the first half of 1982 were estimated based on the patterns observed for the previous years. This record linkage was done by Dr. R.H. Ward, Department of Medical Genetics, University of British Columbia.

\section{b) Migration}

Data from Statistics Canada on migration patterns for the B.C. population show that approximately $2.5 \%$ of the population emigrate annually. The conditional probability of identified cases leaving B.C. was calculated and this resulted in a $7.4 \%$ loss of the study population believed to be alive on prevalence date.

\section{c) Final Prevalence Estimates}

Prevalence rates were estimated for males and females, taking death and the probability of migration into account. Rates cited in this paper are given per 100,000 population and are expressed by the clinical classification of definite/probable MS, possible MS, and optic neuritis.

The prevalence rates given are for B.C. and are also standardized to the general population of Canada.

\section{Results}

\section{Case Identification}

\section{a) Sources of Case Identification}

Table 1 lists the primary sources of case identification. Any patient identified through a neurologist was listed under this category even if they were also ascertained from another source, e.g. self referral. Patients shown in Table 1 to be identified through "other physicians or specialized facilities" were not on the caseloads of neurologists who participated in the study. Self referrals refer to persons who did not identify any medical contact in B.C. This group accounted for only $1.5 \%$ of the study population. $98.5 \%$ of persons were identified through sources where medical documentation of the illness was available. The search of neurologists' files from their offices and the MS Clinic contributed $89 \%$ of included cases.

\section{b) Search of Neurologists' Files}

Neurologists differed with respect to the number of years in practice, and whether or not old files were destroyed. Files of some neurologists covered 20 years or more while other neurologists had records for only a few years of practice. It was thus impossible to assess any change in frequency of MS diagnosis over time.

\begin{tabular}{lrc}
\hline Table 1: Sources of Case Identification & & \\
\hline \hline & Number & Percent of Total \\
\hline $\begin{array}{l}\text { Neurologists } \\
\text { 1. File search }\end{array}$ & 3,892 & 84.2 \\
2. MS Clinic \\
$\begin{array}{l}\text { Other Physicians \& } \\
\quad \text { Medical Facilities }\end{array}$ & 220 & 4.8 \\
$\begin{array}{l}\text { Patient Self Referrals } \\
\text { (Medical documentation }\end{array}$ & 439 & 9.5 \\
not available) & & \\
$\quad$ TOTAL & 69 & 1.5 \\
\hline
\end{tabular}

A total of 239,412 files were reviewed by the same research assistant. 4,874 of these files (2.0\%) represented individuals who fell into one of the categories for inclusion in this study. Once duplicate entries were taken into account, a total of 4,112 persons were identified from this search (3,982 from office files, 220 from the MS Clinic). An additional 508 cases were not documented by neurologists but were identified from other sources for a total of 4,260 person (Table 1).

\section{c) Demographic Characteristics}

The majority of identified cases were female and the mean age of the population at prevalence date was 44.7 years with a median age of 43 years. We included 14 cases under age 15 and 5 cases over age 75 as these had been well documented and firmly diagnosed by neurologists.

\section{d) Death and Migration}

Cross reference with provincial death lists for the years 1940 to 1980 inclusive revealed that 188 cases died prior to the prevalence date and were therefore excluded. The mean age of death was 52.5 years with a distribution from 23 years to 79 years. The average time between diagnosis and death was 7.8 years, compared with a mean follow up for the whole study group of 6.1 years.

A further $7.4 \%$ reduction of the study population was incurred by applying the conditional probability of migration to all cases believed to be alive but not confirmed to still be living in B.C. on the prevalence date.

With these corrections for death and migration, 4,104 cases remained for analysis (Table 2). The $\mathbf{4 7 2}$ cases falling into classifications "MS - a differential diagnosis" and "diagnosis uncertain pending further developments" were not included in

\begin{tabular}{lcc}
\hline Table 2: Diagnostic Classification of the Study Population \\
\hline \hline MS “Classification” & $\begin{array}{c}\text { Number of } \\
\text { Cases* }\end{array}$ & $\begin{array}{c}\text { Percent of } \\
\text { Total }\end{array}$ \\
\hline Definite/Probable MS & 2,596 & 63.3 \\
Possible MS & 744 & 18.1 \\
Optic Neuritis & 292 & 7.1 \\
MS - a differential diagnosis & 446 & 10.9 \\
Diagnosis uncertain pending & & \\
$\quad$ further developments & $\underline{26}$ & 0.6 \\
$\quad$ TOTAL & 4,104 & 100.0 \\
\hline
\end{tabular}

*Numbers after adjustments were made for death and migration. 
the calculation of final prevalence estimates for definite/probable/possible multiple sclerosis and optic neuritis.

\section{Prevalence Data}

As previously stated, prevalence rates were estimated for those persons with a diagnosis of definite/probable MS, possible MS, or optic neuritis. This group consisted of 3,632 individuals, $88.5 \%$ of those listed in Table 2 . Females predominated by a $2.2: 1$ ratio $(2,498$ females, 1,134 males). Table 3 is a breakdown of these cases by sex and diagnostic category with sex-specific prevalence estimates. Table 4 shows cumulative prevalence estimates for the study population.

\section{Multiple Sclerosis and Neurological Practice}

For the subsequent analyses, all identified cases $(N=4,620)$ were used since the results are not affected by the subsequent death or migration of a patient.

Information on the age at which cases first presented to neurologists with symptoms was available on 3,753 patients.

Table 3: Sex-Specific Prevalence Estimates* for multiple sclerosis in British Columbia

\begin{tabular}{lccc}
\hline \hline & $\begin{array}{c}\text { Definite/ } \\
\text { Probable MS }\end{array}$ & $\begin{array}{c}\text { Possible } \\
\text { MS }\end{array}$ & $\begin{array}{c}\text { Optic } \\
\text { Neuritis }\end{array}$ \\
\hline Males & & & \\
$\quad$ Number & 827 & 213 & 94 \\
$\quad$ Prevalence/100,000 & 59.8 & 15.4 & 6.8 \\
Females & & & \\
$\quad$ Number & 1,769 & 531 & 198 \\
$\quad$ Prevalence/100,000 & 126.4 & 37.9 & 14.1 \\
Total & & & \\
$\quad$ Number & 2,596 & 744 & 292 \\
$\quad$ Prevalence/100,000 & 93.3 & 26.7 & 10.5 \\
\hline
\end{tabular}

*Death and migration are taken into account in the estimate of prevalence.

Table 4: Cumulative Prevalence Rates for Multiple Sclerosis in British Columbia

\begin{tabular}{|c|c|c|c|}
\hline & $\begin{array}{c}\text { Definite/ } \\
\text { Probable } \\
\text { MS }\end{array}$ & $\begin{array}{c}\text { Definite/ } \\
\text { Probable } \\
\text { MS PLUS } \\
\text { Possible } \\
\text { MS }\end{array}$ & $\begin{array}{c}\text { Definite/ } \\
\text { Probable } \\
\text { PLUS } \\
\text { Possible } \\
\text { MS PLUS } \\
\text { Optic } \\
\text { Neuritis }\end{array}$ \\
\hline \multicolumn{4}{|l|}{ Males } \\
\hline Number & 827 & 1,040 & 1,134 \\
\hline Cumulative Prevalence $/ 100,000$ & 59.8 & 75.2 & 81.9 \\
\hline \multicolumn{4}{|l|}{ Females } \\
\hline Number & 1,769 & 2,300 & 2,498 \\
\hline Cumulative Prevalence/100,000 & 126.4 & 164.3 & 178.4 \\
\hline \multicolumn{4}{|l|}{ TOTAL } \\
\hline Number & 2,596 & 3,340 & 3,632 \\
\hline Cumulative Prevalence/100,000 & 93.3 & 120.4 & 130.5 \\
\hline \multicolumn{4}{|l|}{ Prevalence Standardized to the } \\
\hline Canadian Population & 91.0 & 117.2 & 127.6 \\
\hline
\end{tabular}

Death and migration are taken into account in the estimate of prevalence.
The age distribution ranges from childhood to the seventh decade. The mean age at first visit was 37 years with a median age of 35 years. The calendar years when patients first consulted these specialists ranged from 1948 to the years of the survey, i.e. 1982-1984. Only those patients whose symptoms were proven to precede the prevalence date were included in this study. An apparent increase in numbers of cases ascertained in more recent years is explained by the destruction of old records by most neurologists therefore making them unavailable for the hand search. In addition, in recent years, several new neurologists entered practice and the MS Clinic was established. It was not possible to determine whether the frequency of a diagnosis of MS or incidence of MS had changed over time.

A diagnosis of definite or probable MS was made in $64.6 \%$ of first patient visits. Possible MS was diagnosed in $10.4 \%$ of first visits. Optic neuritis accounted for the diagnosis in $9.1 \%$ of first consultations. The frequency of a definite or probable diagnosis of MS rose to $83.9 \%$ and $86.3 \%$ in second and third consultations respectively. $76 \%$ of patients eventually diagnosed as definite/probable MS had this diagnosis made on the first neurological visit.

For those individuals who were not diagnosed as having definite/probable MS but who eventually were given this diagnosis, the mean time to reach this diagnosis was 3.3 years. Of 347 cases presenting with optic neuritis, $12 \%$ proceeded to symptoms of more definite MS. The average time between an initial diagnosis of optic neuritis and a diagnosis of possible or definite/probable MS was 2.6 years.

\section{Discussion}

The prevalence estimates for MS reported in this paper are among the highest reported in Canada or elsewhere. During the past two decades, limited prevalence studies have been done in various Canadian Centres. ${ }^{4,5,10-13}$ The results from these stud. ies compared to the current one are summarized in Table 5.

The relatively high prevalence rate for Saskatoon ${ }^{5}$ probably reflects the fact that it is the only completed study designed to

Table 5: Reported Prevalence of Multiple Sclerosis in Canadian Centres

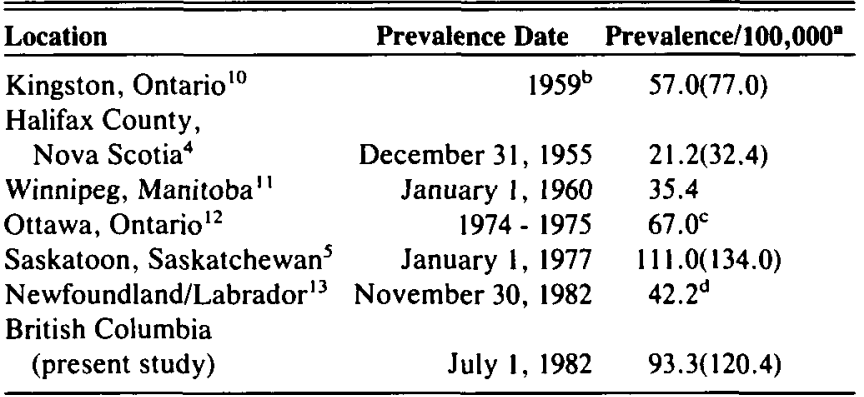

aIf two rates are given, the first refers to definite/probable MS and the second includes possible cases of MS.

${ }^{b}$ The paper was published in 1959. Neither a prevalence date nor years during which the study was conducted were stated. The census data were from 1941.

'This study was not designed as a prevalence study and the rate cited is a "crude" rate.

${ }^{\mathrm{J}}$ Preliminary results only. 
investigate prevalence done since the publication of the Schumacher Committee diagnostic criteria for MS in living patients, ${ }^{7}$ the availability of various diagnostic tests to assist in the diagnosis of MS in the living patient, ${ }^{6}$ and the institution of a universal coverage of medicare system in Canada designed to give all persons essentially equal financial access to medical care and diagnostic procedures. The Ottawa study ${ }^{12}$ was not designed to calculate prevalence and the Newfoundland/Labrador survey ${ }^{13}$ is still in progress and only very preliminary results are available.

The prevalence of MS varies throughout the world but areas of high prevalence include the British Isles and northern Europe. ${ }^{14}$ MS is rare among persons of Asian, African, and Native Indian ancestry. ${ }^{14}$ To allow comparison of the prevalence estimates for B.C. by researchers in other jurisdictions, information on the ethnic origins by the B.C. population is useful. ${ }^{15}$ The B.C. population is largely made up of persons of British (59.6\%) and other European (28.6\%) origins. $4.5 \%$ of the population is of Asian ancestry and 3.0\% are of Native Indian ancestry. The remainder of the population $(4.3 \%$ ) consists of a variety of ethnic groups. At this stage, we have not yet determined the prevalence amongst different ethnic groups in the province.

Two factors may contribute to the high prevalence of MS in B.C. First, the population of the province is largely made up of persons having British and northern European ancestry. The genetic predispositon of these individuals is probably a factor. Second, the geographic location is also a factor since B.C. is located in a northern latitude. The prevalence of MS has been observed to be higher in northern latitudes compared with southern latitudes. ${ }^{16}$

The female:male ratio in the study population is more than 2:1, higher than that often reported $-1.8: 1{ }^{17}$ The female:male ratio for the general population of B.C. is $1.01: 1 .^{15}$ We believe that this excess of females is a valid observation since cases are not self-reporting and the ratio remains high even for the group with definite/probable MS identified through neurologists.

In conclusion, the prevalence estimates for MS in B.C. are among the highest reported and $89 \%$ of the study population had the diagnosis confirmed by neurologists. The high proportion of neurologist confirmed cases of MS makes B.C. a suitable location to persue further epidemiological studies of M.S.

\section{ACKNOWLEDGEMENTS}

This research was funded by grants from the British Columbia Medical Services Foundation and the Mr. and Mrs. P.A. Woodward Foundation.
The authors would like to thank Dr. Ryk Ward, Dr. Annette Stark and Mr. John Spinelli for their assistance with this study. We also gratefully acknowledge the assistance of physicians practicing in the province of British Columbia, especially the neurologists.

\section{REFERENCES}

1. McDonald WI. Multiple Sclerosis: the present position. Acta Neurol Scand 1983; 68: 65-76.

2. Ebers GC. Genetic factors in multiple sclerosis. Neurol Clinics 1983; 1: 645-654

3. Ebers GC, Bulman D, Sadovnick AD et al. A population based twin study in multiple sclerosis. (Abstract) Am J Hum Genet 1984; 36: 49S.

4. Alter M, Allison RS, Talbert OR et al. The geographic distribution of multiple sclerosis. A comparison of prevalence in Charleston County, South Carolina and Halifax County, Nova Scotia. NS Med Bull 1960; 29: 203-210.

5. Hader WJ. Prevalence of multiple sclerosis in Saskatoon. Can Med Assoc J 1982; 127: 295-297.

6. Poser CM. The diagnostic process in multiple sclerosis (Chap 1). In: Poser CM, ed. The Diagnosis of Multiple Sclerosis. New York: Thieme Stratton Inc., 1984; pp3-13.

7. Schumacher GA, Beebe G, Kibler RK et al. Problems of experimental trials of therapy in multiple sclerosis. Report by the panel on the evaluation of experimental trials of therapy in multiple sclerosis. Ann NY Acad Sci 1965; 122: 552-568.

8. Rose AS, Ellison GW, Myers LW et al. Criteria for the clinical diagnosis of multiple sclerosis. Neurology 1976; 26: 20-22.

9. McDonald WI, Halliday AM. Diagnosis and classification of multiple sclerosis. Br Med Bull 1977; 33: 4-8.

10. White DN, Wheelan L. Disseminated sclerosis. A survey of patients in the Kingston Ontario area. Neurology 1959; 9: 256-272.

11. Stazio A, Kurland LT, Bells LG et al. Multiple sclerosis in Winnipeg, Manitoba. Methodological considerations of epidemiologic survey. Ten year follow up of a community wide study and population survey. J Chron Dis 1964; 17: 415-438.

12. Bennett J, Hamilton R, Neutel CL et al. Survey of persons with multiple sclerosis in Ottawa, 1974-1975. Can J Public Health 1977; 68: 141-147.

13. Pryse-Phillips WEM, Cook SD, Galway B. Incidence and prevalence of multiple sclerosis in Newfoundland and Labrador: Baseline results. (Abstract) Can J Neurol Sci 1983; 10: 111.

14. Kurtzke JF. Epidemiologic contributions to multiple sclerosis: An overview. Neurology $1980 ; 30 ; 61-79$.

15. Statistics Canada. 1981. Census Information.

16. Visscher BR, Detels R, Coulson AH et al. Latitude, migration, and the prevalence of multiple sclerosis. Am J Epidemiol 1977; 106: 470-475.

17. Baum HM, Rothschild BB. The incidence and prevalence of reported multiple sclerosis. Ann Neurol 1981; 10: 420-428. 